\title{
Role of titrated low dose oral misoprostol solution in induction of labour
}

\section{Sarvottma Antil*, Usha Gupta}

Department of Obstetrics and Gynaecology, Lady Hardinge Medical College, Delhi, India

Received: 12 January 2016

Accepted: 08 February 2016

\section{*Correspondence:}

Dr. Sarvottma Antil

E-mail: sarvottma_antil@yahoo.com

Copyright: ( $)$ the author(s), publisher and licensee Medip Academy. This is an open-access article distributed under the terms of the Creative Commons Attribution Non-Commercial License, which permits unrestricted non-commercial use, distribution, and reproduction in any medium, provided the original work is properly cited.

\section{ABSTRACT}

Background: Oxytocin is a time tested drug used for induction of labour. However, certain disadvantages associated with oxytocin can be countered if misoprostol is used for the same purpose. But excessive uterine contractility has been a cause of concern with misoprostol use. Based on pharmacological profile of misoprostol, this study was carried out using oral misoprostol solution for induction of labour in low dose, titrated according to uterine contractions and the outcomes were compared with oxytocin.

Methods: A total of 157 women fulfilling inclusion and exclusion criteria were enrolled in the study and cervical ripening was carried out. After the cervix became favorable (Bishop Score $>6$ ), a total of 54 women received titrated oral low dose misoprostol (group 1), and 52 received intravenous oxytocin (group 2). Both the drugs were compared in terms of labour outcomes, efficacy, adverse effects and neonatal outcomes.

Results: There was no significant difference in the mean induction to onset of labour interval and mean induction to delivery interval in group 1 and group 2. Also, there was no significant difference in the modes of delivery and adverse effects and neonatal outcomes in both the groups, except group 1 had a significantly lower incidence of neonates with Apgar score $<7$ at $5 \mathrm{~min}$.

Conclusions: For induction of labour in women with term gestation after cervical priming, low dose oral misoprostol solution in titrated doses and intravenous oxytocin were found to be comparable with each other in terms of labour outcomes, efficacy and adverse effects.

Keywords: Misoprostol, Oxytocin, Dose, Induction, Labour

\section{INTRODUCTION}

Induction of labour is the artificial initiation of labour pains before the spontaneous onset of the same. Once the cervix becomes favourable, various options for induction of labour are available. Out of these, intravenous oxytocin has been widely used in titrated doses for induction of labour. The use of oxytocin has certain disadvantages such as invasive mode of administration (intravenous), restriction of mobility of the pregnant woman, lack of stability at room temperature, just to name a few.
The use of misoprostol in pregnancy has been well established as an abortifacient. Recently various trials ${ }^{1-6}$ have been carried out in which misoprostol has been used for induction of labour in a fixed dosage regimen. Misoprostol has several advantages over oxytocin, such as longer shelf life, stability at room temperature and easy administration by various routes. Yet, excessive uterine contractility resulting in foetal distress has always been a cause of concern associated with the use of misoprostol in induction of labour.

The pharmacological study of misoprostol has revealed significant differences in pharmacokinetics of misoprostol when used orally as compared to vaginally. ${ }^{7}$ 
This difference has implications on efficacy and adverse effects associated with this drug. This observation has prompted various studies using misoprostol in low doses as oral titrated solution and it has been found to be safer in terms of incidence of uterine hyperstimulation and fetal distress. ${ }^{8-11}$ Based on these findings, this study was carried out in women with Bishop Score $>6$, using low dose titrated oral misoprostol solution for induction of labour. This method of induction was compared with titrated intravenous oxytocin in terms of labour outcomes, efficacy, adverse effects and neonatal outcomes.

\section{METHODS}

This prospective, open label randomized controlled trial was conducted in the antenatal ward and the labour room of Department of Obstetrics and Gynaecology of Lady Hardinge Medical College and Smt. Sucheta Kriplani Hospital, New Delhi from November 2011 to March 2013. The study protocol was approved by the institutional review board.

The women due for induction of labour were screened for the study. After initial evaluation (detailed history taking, examination and reviewing investigations), the following inclusion and exclusion criteria of the study were applied to these women.

\section{Inclusion criteria}

- Women due for induction of labour with unfavourable cervix (Bishop Score $\leq 6$ ) at the time of entry into the study

- $\quad 37$ to 42 weeks of gestation by date of last menstrual period, or by first trimester ultrasound

- Singleton pregnancy

- Cephalic presentation

- Reassuring fetal heart rate

\section{Exclusion criteria}

- Antepartum haemorrhage

- History of uterine surgery

- Uncontrolled diabetes mellitus

- Severe and/or uncontrolled pre-eclampsia or eclampsia

- Significant maternal cardiac, hepatic or renal disease, asthma, glaucoma

- Hypersensitivity to misoprostol or prostaglandin analogues

- Refusal to participate in the study

A total of 157 women satisfying the inclusion and exclusion criteria gave consents to participate in the study and signed a written detailed consent form. Randomization was done using random number table. Sealed envelopes with sequential numbering were prepared. These envelops had direction regarding allocation of treatment (misoprostol or oxytocin) to enrolled women inside them. For each participant a separate envelop was opened sequentially, and thus, woman was treated according to directions given in the envelope, unless clinical findings directed otherwise, as described subsequently. Therefore, the participating women were randomized into 2 groups,

Group 1: study group-titrated oral misoprostol solution group

Group 2: control group-titrated intravenous oxytocin group

Blinding was not possible due to clear differentiation in the modes of administration of misoprostol solution and oxytocin. This study was not placebo controlled.

After dividing the participating women into above mentioned two groups by randomization, cervical ripening was carried out in both the groups by using intracervical $\mathrm{PGE}_{2}$ gel (dinoprostone $0.5 \mathrm{mg}$ ), up to a maximum of two doses, given six hours apart. The women whose cervix was still unfavourable (Bishop Score $\leq 6$ ) even after two doses of dinoprostone, were treated according to hospital protocol. Those women who developed labour pains after one or two doses of dinoprostone gel (defined as regular painful uterine contractions with a frequency of $\geq 2$ contractions per 10 minutes, each lasting for at least 20 seconds) were managed according to hospital protocol. Out of the 157 consenting women enrolled in the study, those 106 women who achieved cervical ripening after one or two doses of $\mathrm{PGE}_{2}$ gel, and had not yet developed labour pains were treated as mentioned below.

\section{Group 1: study group-titrated oral misoprostol solution}

A total of 54 women in group 1 developed a favorable cervix after one or two doses of $\mathrm{PGE}_{2}$ gel, but had not developed labour pains. For each of these 54 women, a 200 microgram misoprostol tablet was dissolved in 200 $\mathrm{ml}$ drinking water to make a solution of 1 microgram per ml. $20 \mathrm{ml}$ of this solution was administered every two hourly for the purpose of induction of labour pains. Timing and strength of contractions was assessed by regular abdominal palpation. The initial dosage was increased to 40 microgram after two doses, and so on, up to a maximum of 100 microgram, if uterine contractions are not found to be adequate. Adequate uterine contractions were defined as $\geq 3$ contractions per 10 minutes, each lasting at least for 30 seconds. The solution was administered till uterine contractions were judged to be adequate and remained well established over one hour. Once such contractions developed, further dose of misoprostol solution was adjusted according to strength of uterine contractions. If adequate uterine contractions developed first, but became inadequate subsequently, hourly dose of misoprostol was started, beginning with 5 microgram/hour, and was doubled to $10 \mathrm{microgram} / \mathrm{hour}$ and to as much as 40 microgram/hour till adequate 
uterine contractions developed again. Once the solution was made, it was used for a maximum period of 12 hours and then discarded. The subjects who did not develop adequate uterine contractions within 12 hours were treated according to hospital protocol.

\section{Group 2: control group - titrated intravenous oxytocin}

A total of 52 women in Group 2 developed a favorable cervix after one or two doses of $\mathrm{PGE}_{2}$ gel, but had not developed labour pains. For each of these 52 women, oxytocin was used for induction of labour at an initial intravenous infusion rate of $2 \mathrm{mIU} /$ minute, and the dose was titrated by doubling the dose every half hourly to 4 $\mathrm{mIU} /$ minute, $8 \mathrm{mIU} /$ minute and so on up to a maximum of $64 \mathrm{mIU} /$ minute, till uterine contractions were judged to be adequate ( $\geq$ three per 10 minutes, each lasting at least for 30 seconds) and remained well established. Once adequate uterine contractions developed, further increase in dosage of oxytocin was omitted and intravenous infusion of oxytocin at same dose was continued.

Therefore, a total of 54 women in group 1 and 52 women in group 2 received the designated treatment, making a total of 106 women. The data collected from these 106 women was recorded and analyzed for outcomes.

\section{Clinical monitoring and care}

Vaginal examination was carried out as and when required. Artificial rupture of membranes was performed at the discretion of the person attending the women in both the groups. Fetal heart rate and uterine activity were monitored regularly. Uterine hyperactivity comprised of one of the following:

- Tachysystole (>5 contractions per 10 minutes for at least a period of 20 minutes)

- Hypersystole (single contraction lasting for at least two minutes)

- Uterine hyperstimulation syndrome (hypersystole or tachysystole with fetal heart rate abnormality)

These conditions were managed conservatively (left lateral positioning, oxygen inhalation by mask, hydration and if needed, tocolysis). Further dose of misoprostol and oxytocin were omitted when hyperstimulation was diagnosed, till the uterine contractions became inadequate and there was no hyperstimulation. Fetal heart rate and uterine contraction were monitored continuously in women with uterine hyperstimulation.

Non-progress of labour was defined as no progress in descent of fetal head or cervical dilation for three hours after entering active phase of labour. Hospital protocol was used to treat all women with non-progress of labour or non-reassuring fetal heart rate (late deceleration, prolonged deceleration, severe variable deceleration, tachycardia, reduced baseline variability) and hence, caesarean section was offered to them. ${ }^{12}$

\section{Outcomes}

The primary outcomes used to compare efficacy of the two drugs were:

- Induction to onset of labour interval (starting from the time of first dose of misoprostol solution in group 1 and oxytocin infusion in group 2 till the onset regular uterine contractions)

- Induction to delivery interval (starting from the time of first dose of misoprostol solution in Group 1 and oxytocin infusion in group 2 till delivery by any route)

The secondary outcomes used to compare efficacy and adverse effects of two drugs were,

- Modes of delivery

- Total dosage of misoprostol and oxytocin

- Uterine hyperactivity

- Maternal side effects (nausea, vomiting, diarrhoea, shivering, pyrexia, headache)

- Neonatal outcomes (Apgar score less than 7 at 5 minutes, admittance to neonatal intensive care unit)

End point of study was delivery of the subject by any mode. The primary and secondary outcomes were compared in those women in group 1 and 2, who received the designated treatment, i.e. misoprostol in group 1 and oxytocin in group 2. The data collected from these 106 women was coded and analyzed. Quantitative data (mean and standard deviation) was assessed by significance tests [Independent sample $t$ - test (unpaired $t$ test)] and $p$ value was calculated. Proportion and chi square test were applied to qualitative data.

\section{RESULTS}

The characteristics of the participating women in both the groups are shown in Table 1. Both the groups were comparable to each other in terms maternal age, period of gestation and initial Bishop Score on admission in trial. As shown in Table 2, there was no significant difference in the parity of participating women in both the groups.

As evident from Table 3, the three most common indications for induction of labour were post-term pregnancy, term pre-labour rupture of membranes and gestational hypertension, in that order. There were no statistically significant differences between both the groups with respect to indications for induction of labour (Table 3). 
Table 1: Characteristics of participants of the study.

\begin{tabular}{|llllll|}
\hline & Group 1 & (N=54) & Group 2 $(\mathbf{N}=52)$ & p value** \\
& $\begin{array}{l}\text { Mean } \\
\text { age }\end{array}$ & $\begin{array}{l}\text { Standard } \\
\text { deviation }\end{array}$ & Mean age & $\begin{array}{l}\text { Standard } \\
\text { deviation }\end{array}$ & \\
\hline Mean maternal age (years) & 24.17 & 2.81 & 24.31 & 3.40 & 0.816 \\
\hline Mean period of gestation (days) & 276.17 & 8.24 & 275.83 & 7.83 & 0.828 \\
\hline Mean initial Bishop Score & 3.63 & 0.9 & 3.56 & 0.80 & 0.84 \\
\hline
\end{tabular}

*student unpaired t- test

Table 2: Parity of women.

\begin{tabular}{|lllll|}
\hline Parity* & Group 1 & $(\mathrm{N}=54)$ & Group 2 & $(\mathrm{N}=52)$ \\
& Number & $\%$ & Number & $\%$ \\
\hline Nullipara & 36 & 66.67 & 33 & 63.46 \\
\hline Multipara & 18 & 33.33 & 19 & 36.54 \\
\hline Total & 54 & 100 & 52 & 100 \\
\hline
\end{tabular}

$*$ p value $=0.729($ Chi-square test $)$

Table 4 shows two primary outcomes (induction to onset of labour \& induction to delivery interval) using mean values. The mean induction to onset of labour interval in group 1 was longer, being $123.33[ \pm 63.75]$ minutes as compared to $104.42[ \pm 49.88]$ minutes of group 2, however, the difference was not statistically significant. Similarly, no significant difference was observed in the mean induction to delivery interval for both the groups, being $375.22[ \pm 178.24]$ minutes in group 1 and 386.85 $[ \pm 189.11]$ minutes in group 2 , respectively $(\mathrm{p}=0.745)$. The mean induction to onset of labour and mean induction to delivery intervals in both the groups showed high values of standard deviation in the present study (Table 4), necessitating the calculation of median values for these parameters (Table 5), which represent the majority of women in both the groups. The median induction to onset of labour interval, i.e., time from the first dose of respective drug till the onset of regular uterine contractions, in group 1 was same as that observed in group 2, being $90 \mathrm{~min}$. in each group. When, however, the median induction to delivery interval was calculated, it was found to be lower in group 1 than in group 2, being $318.5 \mathrm{~min}$ and $347.5 \mathrm{~min}$ respectively, the difference however, was not statistically significant $(\mathrm{p}=$ 0.788).

When the modes of delivery were compared in the two groups, it was observed that more than three fourth of the patients in both the groups had a normal vaginal delivery (Table 6). It was found that though a greater number of women in group $1(85.19 \%)$ had a normal vaginal delivery as compared to those in group $2(78.85 \%)$, the difference did not reach statistical significant $(p=0.234)$ (Table 6). Also, there was no significant difference in the incidence of caesarean delivery in both the groups, being $11.11 \%$ in group 1 and $17.31 \%$ in group $2(\mathrm{p}=0.096)$ (Table 6). Both the groups had the same number of instrumental vaginal delivery (outlet forceps), i.e. 2 in each group $(p=0.999)$. Indication for instrumental vaginal delivery in all the women in both the groups was foetal distress with maternal exhaustion in second stage of labour.

Table 3: Indication for induction of labour.

\begin{tabular}{|c|c|c|c|c|c|}
\hline \multirow[t]{2}{*}{ Indication } & \multicolumn{2}{|c|}{ Group $1(\mathrm{~N}=54)$} & \multicolumn{2}{|c|}{ Group $2(\mathrm{~N}=52)$} & \multirow[t]{2}{*}{ p value } \\
\hline & Number & $\%$ & Number & $\%$ & \\
\hline Post-term pregnancy & 22 & 40.74 & 21 & 40.38 & 0.942 \\
\hline Term premature rupture of membranes & 12 & 22.22 & 12 & 23.08 & 0.999 \\
\hline Gestational hypertension & 7 & 12.96 & 8 & 15.38 & 0.884 \\
\hline Rh negative pregnancy & 6 & 11.11 & 5 & 9.62 & 0.746 \\
\hline Decreased fetal movements & 3 & 5.56 & 2 & 3.85 & 0.545 \\
\hline Fetal growth restriction & 3 & 5.56 & 3 & 5.77 & 0.999 \\
\hline Oligohydroamnios & 1 & 1.85 & 1 & 1.92 & 0.999 \\
\hline Total & 54 & 100 & 52 & 100 & \\
\hline
\end{tabular}


Table 4: Primary outcomes (mean values).

\begin{tabular}{|llllll|}
\hline & Group 1 $(\mathrm{N}=54)$ & Group 2 (N=52) & \multicolumn{2}{c|}{ p value* } \\
\hline & $\begin{array}{l}\text { Mean time } \\
\text { (min.) }\end{array}$ & $\begin{array}{l}\text { Standard } \\
\text { deviation }\end{array}$ & $\begin{array}{l}\text { Mean time } \\
\text { (min.) }\end{array}$ & $\begin{array}{l}\text { Standard } \\
\text { deviation }\end{array}$ \\
\hline Induction to onset of labour interval & 123.33 & 63.75 & 104.42 & 49.88 & 0.093 \\
\hline Induction to delivery interval & 375.22 & 178.24 & 386.85 & 189.11 & 0.745 \\
\hline
\end{tabular}

Table 5: Primary outcomes (median values)

\begin{tabular}{|lccccc|}
\hline Median Values & $\begin{array}{c}\text { Median time } \\
(\mathrm{min})\end{array}$ & $\begin{array}{c}\text { Interquartile } \\
\text { range }\end{array}$ & $\begin{array}{c}\text { Median time } \\
(\text { min. })\end{array}$ & $\begin{array}{c}\text { Interquartile } \\
\text { range }\end{array}$ & p value* \\
\hline $\begin{array}{l}\text { Induction to onset of labour } \\
\text { interval }\end{array}$ & 90 & $90-150$ & 90 & $60-120$ & 0.991 \\
\hline $\begin{array}{l}\text { Induction to delivery } \\
\text { interval }\end{array}$ & 318.5 & $244-456$ & 347.5 & $243-534$ & 0.788 \\
\hline *Wilcoxon rank sum test & & & & &
\end{tabular}

*Wilcoxon rank sum test

Table 6: Secondary outcome-mode of delivery

\begin{tabular}{|llllll|}
\hline Mode of delivery & Group 1 & $(\mathrm{N}=54)$ & \multicolumn{2}{l|}{ Group 2 $(\mathbf{N}=52)$} & p value* \\
\hline & Number & $\%$ & Number & $\%$ & \\
\hline Vaginal Delivery (A) & 46 & 85.19 & 41 & 78.85 & 0.234 \\
\hline Operative Delivery & & & & & \\
Instrumental (Outlet Forceps) (B) & 2 & 3.70 & 2 & 3.85 & 0.999 \\
Caesarean section (C) & 6 & 11.11 & 9 & 17.31 & 0.096 \\
\hline Total (A + B + C) & 54 & 100 & 52 & 100 & \\
\hline *Fisher exact test & & & & & \\
\hline
\end{tabular}

The mean total dose of respective drugs received by women, for induction of labour, till delivery was 77.13 $[ \pm 37.06] \mathrm{mcg}$ of misoprostol in group 1 and 18551.7 [ \pm 12394.9$] \mathrm{mIU}$ of oxytocin in group 2 . On calculating the median total dose of respective drugs administered till delivery, which represented the total amount of drug used for majority of women in both the groups, it was found to be $80 \mathrm{mcg}\{$ I.R. $=40-12\}$ for misoprostol in group 1 (54 women) and $16360 \mathrm{mIU}$ \{I.R. 7800-28312\} for oxytocin in group 2 (52 women).

Out of the 46 women in group 1 who had normal vaginal delivery, 19 women required misoprostol in a dose of $\leq 40$ mcg, 18 women needed a dose $>40 \mathrm{mcg}$ but $\leq 80 \mathrm{mcg}$ (Table 7). Therefore it was observed that almost $80 \%$ of the women who had normal vaginal delivery after being given titrated low dose oral misoprostol solution required a total dose of $\leq 80 \mathrm{mcg}$ of misoprostol for delivery (Table 7).

When similar data was calculated for group 2, it was observed that out of 41 women, who had normal vaginal delivery in this group, 11 women required oxytocin in a total dose of $<10000 \mathrm{mIU}$ and 17 women needed a dose between 10000-20000 mIU (Table 8). Therefore it was observed that more than two third of the women who had normal vaginal delivery after being given intravenous oxytocin, required a total dose of $<20000 \mathrm{mIU}$ of oxytocin for delivery.

Table 7: Secondary outcome- total dose of misoprostol in women with normal vaginal delivery.

\begin{tabular}{|lcc|}
\hline $\begin{array}{l}\text { Dose of misoprostol } \\
(\mathrm{mcg})\end{array}$ & \multicolumn{2}{c|}{ Group 1} \\
\hline & Number & $\%$ \\
\hline$\leq 40$ & 19 & 41.30 \\
\hline$>40, \leq 80$ & 18 & 39.13 \\
\hline$>80, \leq 120$ & 7 & 15.22 \\
\hline$>120$ & 2 & 4.35 \\
\hline Total & 46 & 100 \\
\hline
\end{tabular}

It was found that out of the 54 women induced with misoprostol in group 1, one had uterine hyperactivity (tachysystole) as compared to three in group 2 (2 had tachysystole and one had hypersystole). Therefore, although, there was a lower incidence of uterine hyperactivity in group $1(1.85 \%)$ as compared to group 2 $(5.77 \%)$, it was not statistically significant $(\mathrm{p}=0.290)$ (Table 9). None of the above mentioned women had 
uterine hyperstimulation syndrome, i.e. foetal heart rate abnormalities associated with uterine hyperactivity (Table 9).

Table 8: Secondary outcome-total dose of oxytocin in women with normal vaginal delivery.

\begin{tabular}{|lll|}
\hline Dose of oxytocin (m]U) & Group 2 $(\mathbf{N = 4 1 )}$ \\
\hline & Number & $\%$ \\
\hline$<10000$ & 11 & 26.83 \\
\hline $10000-19999$ & 17 & 41.46 \\
\hline $20000-29999$ & 8 & 19.51 \\
\hline $30000-39999$ & 2 & 4.88 \\
\hline$\geq 40000$ & 3 & 7.32 \\
\hline Total & 41 & 100 \\
\hline
\end{tabular}

As for other maternal side effects, no significant difference was found between the two groups in terms of various maternal side effects $(\mathrm{p}<0.05)$ (Table 10). The most common maternal side effect noted in both the groups was shivering, its incidence being $16.67 \%$ in group 1 and $17.31 \%$ in group 2. The second most common side effect noted in both the groups was nausea with $14.81 \%$ women from group 1 and $11.54 \%$ women in group 2 reporting this side effect, the difference being insignificant ( $\mathrm{p}=0.721)$. Vomiting was almost three times more common in group 1, being present in $12.96 \%$ women, as compared to $3.85 \%$ in group 2. This difference, also, did not reach statistical significance $(\mathrm{p}=0.072)$. Headache was not reported by any women in group 1, while it was reported by 2 women in group 2 who received a total dose of more than $40,000 \mathrm{mIU}$ of oxytocin. Diarrhoea and pyrexia (temperature $>38$ degree Celsius) were not observed in any women both the groups in the present study.

On analysing the neonatal outcomes in this study, low dose oral misoprostol was associated with a significantly lower incidence of Apgar score of neonate $<7$ at 5 minutes as compared to oxytocin, being $0 \%$ in Group 1 and $7.69 \%$ in group $2(\mathrm{p}=0.038)$ (Table 11). No significant difference was noted in the NICU admission in both the groups, being $3.7 \%$ and $7.69 \%$ in group 1 and group 2 respectively.

Table 9: Secondary outcome-number of women showing uterine hyperactivity.

\begin{tabular}{|c|c|c|c|c|c|}
\hline \multirow[t]{2}{*}{ Uterine hyperactivity } & \multicolumn{2}{|c|}{ Group $1(\mathbf{N}=54)$} & \multicolumn{2}{|c|}{ Group $2(\mathrm{~N}=52)$} & \multirow[t]{2}{*}{ p value* } \\
\hline & Number & $\%$ & Number & $\%$ & \\
\hline Tachysystole & 1 & 1.85 & 2 & 3.85 & 0.581 \\
\hline Hypersysytole & 0 & 0 & 1 & 1.92 & 0.324 \\
\hline Uterine hyperstimulation syndrome & 0 & 0 & 0 & 0 & N.A. \\
\hline Total & 1 & 1.85 & 3 & 5.77 & 0.290 \\
\hline
\end{tabular}

*Fisher exact test

Table 10: Secondary outcome-maternal side effects.

\begin{tabular}{|c|c|c|c|c|c|}
\hline Adverse Effect & \multicolumn{2}{|c|}{ Group $1(\mathbf{N}=54)$} & \multicolumn{2}{|c|}{ Group $2(\mathrm{~N}=52)$} & p value \\
\hline Maternal & Number & $\%$ & Number & $\%$ & \\
\hline Shivering & 9 & 16.67 & 9 & 17.31 & 0.999 \\
\hline Nausea & 8 & 14.81 & 6 & 11.54 & 0.721 \\
\hline Vomiting & 7 & 12.96 & 2 & 3.85 & 0.072 \\
\hline Pyrexia ${ }^{\#}$ & 0 & 0 & 0 & 0 & N.A. \\
\hline Diarrhoea & 0 & 0 & 0 & 0 & N.A. \\
\hline Headache & 0 & 0 & 2 & 3.85 & 0.146 \\
\hline
\end{tabular}

\#Temperature > 38 degree Celsius *Fisher exact test

Table 11: Secondary outcome-neonatal outcomes.

\begin{tabular}{|c|c|c|c|c|c|}
\hline & \multicolumn{2}{|c|}{ Group $1(N=54)$} & \multicolumn{2}{|c|}{ Group $2(\mathrm{~N}=52)$} & \multirow[t]{2}{*}{ p value } \\
\hline & Number & $\%$ & Number & $\%$ & \\
\hline Apgar score $<7$ at $5 \mathrm{~min}$. & 0 & 0 & 4 & 7.69 & 0.038 \\
\hline NICU/nursery admission & 2 & 3.70 & 4 & 7.69 & 0.504 \\
\hline
\end{tabular}

*Fisher Exact Test 


\section{DISCUSSION}

Oxytocin has been a time tested drug used for induction of labour. However, certain disadvantages have been associated with oxytocin use like need to administer it by intravenous route, lack of stability at room temperature, shorter shelf life and being relatively expensive. On the other hand, misoprostol has advantages of being easy to use, convenient administration by various routes like the vaginal, sublingual and oral, being stable at room temperature, having a longer shelf life and being relatively inexpensive. Although misoprostol has been commonly used for inducing abortions in first and second trimester, still, its obstetrical use for induction of labour in women with term gestation and live fetus has not been as widespread. There have been very few studies to observe labour outcomes in patients induced with titrated low dose oral misoprostol solution. Therefore, the present study was conducted with the aim of studying the role of titrated low dose oral misoprostol solution for induction of labour at term, and comparing it with titrated intravenous oxytocin.

When the data pertaining to primary outcomes (used to compare efficacy of the two drugs) was analyzed, statistically insignificant difference was noted in the mean and median values of induction to onset of labour $\&$ induction to delivery interval (Table 4 and Table 5). This leads to a conclusion that low dose misoprostol and oxytocin have a comparable effect on induction of labour in women with favorable cervix.

On comparing the modes of delivery, it was observed that the two groups did not have any significant difference in terms of rates of normal vaginal delivery, instrumental delivery or caesarean delivery (Table 6). Thus, from these results it appears that misoprostol is as effective as oxytocin for induction of labour, resulting in normal vaginal delivery, in women with favorable cervix. Also, these results point out that titrated low dose oral misoprostol solution is not associated with an increased incidence of caesarean delivery, when compared with titrated intravenous oxytocin.

Incidence of uterine hyperactivity was an important parameter in assessing adverse effects of both the drugs. No significant difference was noted between the two groups in the rate of uterine hyperactivity in the present study, being $1.85 \%$ in group 1 and $5.77 \%$ in group $2(\mathrm{p}=$ $0.290)$. This result eliminates the anxiety regarding the association of uterine hyperactivity with misoprostol use when given as a titrated low dose oral solution. This observation establishes the use of titrated low dose oral misoprostol solution to be as safe as oxytocin in terms of incidence of uterine hyperactivity.

In the present study, $1.85 \%$ of the women who received misoprostol (group 1) had uterine hyperactivity. This was much lower than the incidence quoted by various authors. $^{8-11}$ The reason for this variation may be associated with the different dosage regimen of misoprostol used in different studies, as well as with different individual response to misoprostol. It is possible that the individual response of women to misoprostol may be dependent on drug absorption, peak levels reached and different action on uterus in different population groups. This aspect deserves further research. Therefore, it appears to be a good practice to carefully monitor uterine contractions and administer misoprostol in doses titrated according to individual response, instead of giving the drug in fixed dose regimens as used in various early clinical trials. ${ }^{1-6}$ These results also emphasize the urgent need to standardize the dose regimen of misoprostol.

In the present study, it was found that misoprostol use was associated with an insignificantly higher incidence of shivering, nausea and GI side effects as compared to oxytocin $(p<0.05)$. Also, an insignificantly lower incidence of maternal headache was associated with misoprostol as compared to oxytocin $(p=0.146)$. Therefore, low dose oral misoprostol and oxytocin were found to be comparable in terms of various maternal side effects. When the median total dose of misoprostol in women who complained of shivering, nausea and/or vomiting was calculated, it was found to be $120 \mathrm{mcg}$ which was higher than the median total dose of misoprostol used in the whole group, i.e., $80 \mathrm{mcg}$. On similar dose related analysis in group 2, median total dose of oxytocin used in women who developed any of these three adverse effects was much higher than the median total dose of oxytocin used in the whole group, i.e., $16360 \mathrm{mIU}$. This implies that for both these drugs, these side effects are dose related.

In the present study, none of the neonates born to the mothers who received misoprostol for induction of labour had an Apgar score $<7$ at 5 minutes. Similar results were seen in the studies conducted by Ho et $\mathrm{al}^{8}$. and Cheng et $\mathrm{al}^{10}$, with none of the neonates in the misoprostol group having an Apgar score of $<7$ at 5 minutes. In all the above mentioned studies, misoprostol was used in low doses. Hence, it can be deduced that when used in low doses, misoprostol is not found to be associated with poor neonatal outcomes as measured by the number of neonates with Apgar score $<7$ at 5 minutes. This study found significantly lower number of neonates with Apgar score of $<7$ at 5 minutes in group 1 (given low dose misoprostol) as compared to group 2 (given oxytocin) in the present study $(\mathrm{p}=0.038)$, while the other authors (Ho et $\mathrm{al}^{8}$. and Aalami-Harandi et $\mathrm{al}^{9}$ ) did not find a significant difference between misoprostol and oxytocin in terms the incidence of neonates with Apgar score of $<7$ at 5 minutes $(\mathrm{p}<0.05)$. This difference may be explained by the fact that the maximum dose of oxytocin used in present study was $64 \mathrm{mIU}$, while that used by Ho et $\mathrm{al}^{8}$. (20 mIU) and Aalami-Harandi et al. ${ }^{9}$ (34 mIU) was much lower. 
In the present study, a total of $3.70 \%$ women in group 1 and $7.69 \%$ women in group 2 had their neonates admitted to NICU/nursery, the difference being statistically insignificant $(p=0.504)$. This shows that the two drugs are comparable to each other in neonatal adverse outcomes in terms of NICU admissions. In the present study, $3.70 \%$ women in group 1 had their neonates admitted to NICU/nursery. These findings were almost similar to those observed by Ho et $\mathrm{al}^{8}$, where the incidence of NICU/nursery admission with misoprostol use was $4.2 \%$. The mean total dose of misoprostol used in women in present study, who had their neonates admitted to NICU/nursery, was $120 \mathrm{mcg}$, which was higher than the mean dose for whole group $(77.13 \mathrm{mcg})$. This shows that use of a higher total dose of misoprostol may increase the chances of neonate to be admitted to NICU/nursery.

Hence, for induction of labour in women with term gestation after cervical priming using $\mathrm{PGE}_{2}$ gel, low dose oral misoprostol solution in titrated doses and intravenous oxytocin were found to be comparable with each other in terms efficacy. Low dose oral misoprostol was also associated with an insignificantly lower incidence of uterine hyperactivity as compared to oxytocin. Both the drugs were comparable in terms of various other maternal side effects (like shivering, nausea, vomiting, diarrhoea, pyrexia and headache). In terms of neonatal outcomes, low dose oral misoprostol solution was associated with a significantly lower incidence of neonates with Apgar score $<7$ at 5 min. as compared to intravenous oxytocin with no significant difference in the NICU/nursery admission associated with both the drugs. Therefore, it can be deduced from this discussion that low dose oral misoprostol solution in titrated doses can be used as a safe and effective alternative of intravenous oxytocin, for induction of labour in women with term gestation after cervical priming using $\mathrm{PGE}_{2}$ gel. So far, different authors have used different doses administered at different intervals which may have contributed to variation in results. Therefore there appears to be an urgent need to standardize the dose regimen of misoprostol.

Funding: No funding sources

Conflict of interest: None declared

Ethical approval: The study was approved by the Institutional Ethics Committee

\section{REFERENCES}

1. Tessier F, Dansereau J. A double-blind randomised controlled trial comparing oral misoprostol to vaginal prostaglandin $\mathrm{E}_{2}$ gel for induction of labour at or near term. Am J Obstet Gynecol. 1997;176:S111.
2. Windrim R, Bennett K, Mundle W, Young DC. Oral administration of misoprostol for labor induction: a randomized controlled trial. Obstet Gynaecol. 1997;89:392-7.

3. Adair CD, Weeks JW, Barrileaux PS, Philbert L, Edward MS, Lewis DF. Labor induction with oral versus vaginal misoprostol: a randomized doubleblind trial. Am J Obstet Gynecol. 1998;178:S93.

4. Kwon JS, Davies GA, MacKenzie VP. A comparison of oral and vaginal misoprostol for induction of labour at term: a randomized trial. $\mathrm{Br} \mathrm{J}$ Obstet Gynaecol. 2001;108:23-6.

5. Wing DA, Ham D, Paul RH. A comparison of orally administered misoprostol for cervical ripening and labor induction. Am J Obstet Gynecol. 1999; 180:1155-60.

6. Toppozada MK, Anwar MYM, Hassan HA, ElGazaerly WS. Oral or vaginal misoprostol for induction of labour. Int $\mathrm{J}$ Gynecol Obstet. 1997;56:135-9.

7. Zeiman M, Fong SK, Benowitz NL, Banskter D, Darney PD. Absorption kinetics of misoprostol with oral or vaginal administration. Obstet Gynecol. 1997;90:88-92.

8. Ho M, Cheng SY, Li TC. Titrated oral misoprostol solution compared with intravenous oxytocin for labor augmentation: a randomized controlled trial. Obstet Gynecol. 2010;116(3):612-8.

9. Aalami-Harandi R, Karamali M, Moeini A. Induction of labor with titrated oral misoprostol solution versus oxytocin in term pregnancy: randomized controlled trial. Rev Bras Ginecol Obstet. 2013;35(2):60-5.

10. Cheng SY, Hsue CS, Hwang GH, Chen W, Li TC. Comparison of labor induction with titrated oral misoprostol solution between nulliparous and multiparous women. J Obstet Gynaecol Res. 2010;36(1):72-8.

11. Cheng SY, Chen TC. Pilot study of labor induction with titrated oral misoprostol. Taiwan J Obstet Gynecol. 2006;45:225-9.

12. Sweha A, Hacker TW, Nuovo J. Interpretation of electronic fetal heart rate during labor. Am Fam Physician. 1999;59:2487-500.

Cite this article as: Antil S, Gupta U. Role of titrated low dose oral misoprostol solution in induction of labour. Int J Reprod Contracept Obstet Gynecol 2016;5:775-82. 